\title{
Premium Quality Mango Genotypes for Extended Harvest Season
}

\author{
Iqrar Ahmad Khan and Ahmad Sattar Khan' \\ Institute of Horticultural Sciences, University of Agriculture, Faisalabad, Pakistan
}

\author{
Ishtiaq Ahmad Rajwana \\ Department of Horticulture, Muhammad Nawaz Shareef University of \\ Agriculture, Multan, Pakistan
}

\begin{abstract}
Asif Ali Khan
Department of Plant Breeding and Genetics, Muhammad Nawaz Shareef University of Agriculture, Multan, Pakistan
\end{abstract}

\section{Muhammad Abubakkar Azmat and Syed Ali Raza \\ University of Agriculture Faisalabad, Subcampus Burewala-Vehari, Pakistan}

Additional index words. Ceratocystis manginecans, Mangifera indica, melting flavor, MQWD, pulp content, shelf life, TSS

\begin{abstract}
Mango (Mangifera indica L.) is delicious and nutritious fruit grown in the tropical and subtropical regions of the world. The IndoPak subcontinent-Myanmar region has been reported as the consensus center of diversity for mango (Yamanaka et al., 2006). Mango in Pakistan is a major fruit crop. Due to appealing organoleptic quality, taste, pleasant aroma, and excellent texture, the demand for Pakistani mangoes is increasing in the international market. Most of the mangoes grown in Pakistan are midseason maturing cultivars (Rajwana et al., 2008). Since all the elite and exportable mango cultivars grown in Pakistan mature during mid-July to midAugust (mid harvest season); leaving the early and late harvest season export windows unattended. In spite of high production, the mango exports from Pakistan are meagre and stagnant. Mango production in Pakistan has been affected due to insect-pest infestation (mainly caused by mango leafhopper, mango mealybug, and fruit fly) and different physiological disorders. Mango quick wilt disease
\end{abstract}

\footnotetext{
Received for publication 16 June 2016. Accepted for publication 11 Oct. 2016.

We gratefully acknowledge the financial support provided by the Punjab Agricultural Research Board (PARB), Pakistan for the research project (PARB-150) "Characterization of native and potential mango varieties in relation to Ceratocystis manginecans and other economic traits." We also thank Agriculture Extension Department Punjab and Azad Jammu and Kashmir, mango growers and breeders for their support during survey and data collection.

We grateful to Professor Zora Singh (Curtin University, Perth, Australia) and Louise Ferguson (UC Davis, United States) for critically reviewing this manuscript.

${ }^{1}$ Corresponding author. E-mail: ahmad_khan157@ yahoo.com.

This is an open access article distributed under the CC BY-NC-ND license (http://creativecommons. org/licenses/by-nc-nd/4.0/).
}

(MQWD) (Ceratocystis manginecans) is now widespread in the commercial fruit producing areas of Pakistan which is a serious threat to the production and cultivation of quality mangoes (van Wyk et al., 2007). Most commercial mango cultivars grown in Pakistan typically propagated by means of seedling selection from the natural populations of indigenous cultivars, which are more prone to MQWD (van Wyk et al., 2007). Therefore, together with limited genetic base of commercial mango cultivars and the growing threat of MQWD, the situation has become more critical.

Pakistan is located at the western periphery of the natural range of monoembryonic mangoes. Pakistan's commercial mango cultivars are mostly selected landrace clones and chance seedlings being propagated by amateur gardeners and nurserymen (Rajwana et al., 2008). Selection of chance seedlings arising from commercial cultivars has been the preferred method of cultivar development (Chaikiattiytos et al., 2000; Khan et al., 2015; Rajwana et al., 2011). Keeping in view the importance of the identification of alternative mango genotypes in relation to disease progression in the mango growing areas with the same legacy of taste and aroma of Pakistani mangoes, a research project was funded by Punjab Agricultural Research Board. An extensive survey was conducted for 4 consecutive years (2010-14) throughout the mango growing areas of Punjab and Azad Jammu and Kashmir. More than 500 diversified seedling trees were tagged and evaluated for different morphological, physicochemical, and molecular traits. At the completion of this project, nine mango genotypes were identified as potential and alternative genotypes for commercial cultivation in mango growing areas with extended harvesting season.

\section{Origin}

Each of the genotype was identified as a chance seedling from orchards of different mango producing districts (Rahim Yar KhanRYK, Khanewal-KHW, and Multan-MLT) of Punjab-Pakistan. Nine diverse genotypes with different maturity periods including early season (RYK-426), midseason (KHW251, MLT-239, MLT-248, and MLT-369), and late season (MLT-658, RYK-265, RYK644, and KHW-250) were used for the present study. To study the physical and biochemical quality, fruit of each genotype were harvested at their respective physiological maturity (based on preliminary experiments) and ripened at ambient condition $\left(25 \pm 2{ }^{\circ} \mathrm{C}\right.$ and $60 \% \pm 5 \%$ relative humidity) until reached fully ripe stage (eating soft). These identified new genotypes exhibited good morphological and organoleptic fruit quality with high pulp content and/or antioxidant. External physical fruit quality characteristics of these genotypes were determined subjectively through visual evaluation. Eating quality of fruit was determined through a panel of 10 judges using a 9 points hedonic scale, where $1=$ dislike extremely and $9=$ like extremely (Peryam and Pilgrim, 1957). From pooled fruit pulp samples, extracted juice filtered through Whatman ${ }^{\circledR}$ No. 1 filter paper (Whatman International Ltd., Maidstone, United Kingdom) was used to determine total soluble solids (TSS), titratable acidity (TA), total sugars, and antioxidant contents. TSS of fruit juice were determined using a digital refractometer (ATAGO, RX 5000, Tokyo, Japan). TA of fruit juice was determined by titrating it against $0.1 \mathrm{NaOH}$ using phenolphthalein as indicator. Total sugars were determined using method of Horwitz (1960). Antioxidant contents were determined by using method as reported by Khan and Singh (2008). The origin of most of the genotypes is not known; however, possibly a limited number of genotypes have arisen from Sindhri (MLT239), Chaunsa (RYK-265), and Anwar Ratole (MLT-248) cultivars. Genomic DNA was extracted from the young tender leaves of nine mango genotypes by using modified cetyltrimethylammonium bromide method (Azmat et al., 2012). The extracted DNA was subjected to DNA fingerprinting by using 120 simple sequence repeat/inter-simple sequence repeat (SSR/ISSR) primers as described by Azmat et al. (2016). These new genotypes could be a useful alternative of the existing mango cultivars with a broadened genetic base.

\section{Description}

RYK-426 is an early-season maturing genotype of southern Punjab (lat. 28 34' 29.73 "N, long. $70^{\circ} 15^{\prime} 50.63^{\prime \prime} \mathrm{E}$ ). The tree has spreading growth habit with broadly pyramidal crown shape (Table 1). Young leaves are light green with brownish tinge, whereas mature leaves are green in color having lanceolate form and entire margin. The inflorescence is broadly pyramidal having pink color (Fig. 1). The fruit is medium in size (320 g average weight) and having $10.6 \mathrm{~cm}$ and $6.9 \mathrm{~cm}$ average length $\times$ breadth, respectively, and an attractive narrowly elliptic shape. The fruit exhibit good eating quality with average 255 TSS:TA ratio and $1.9 \mathrm{~mm}$ 


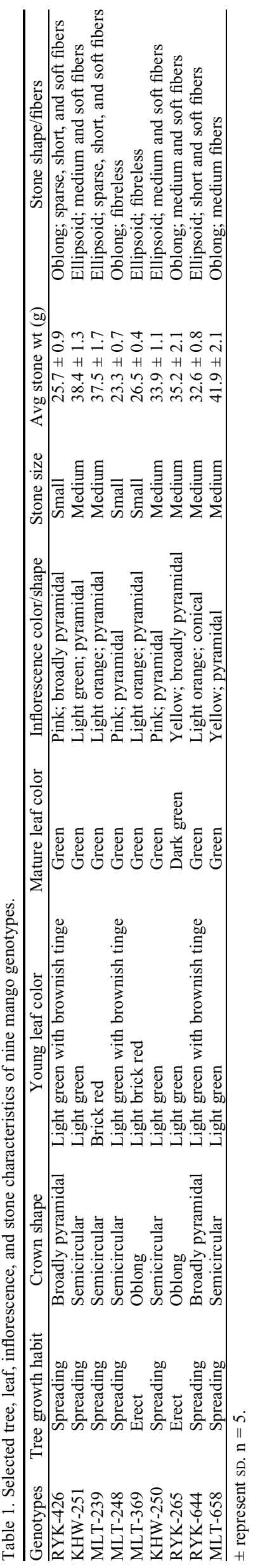

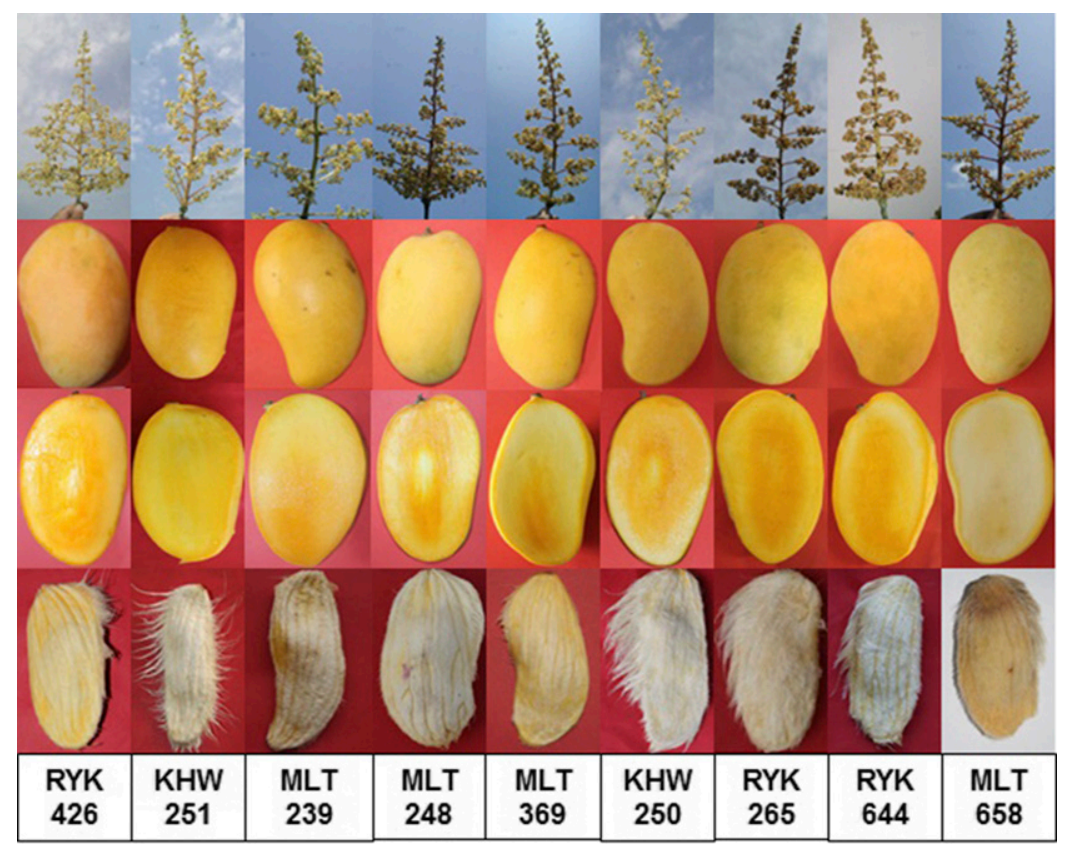

Fig. 1. Inflorescence, fruit, and stone characteristics of nine mango genotypes.

Trolox/g FW average antioxidant contents (Table 2). The stone is small, oblong covered with sparse, short and soft fibers. The DNA fingerprints of RYK-426 by using 120 SSR primers are also available for its profiling. The genotype-specific marker (MiIIHR15) has also been identified for RYK-426 (Table 3).

KHW-251 is an attractive midseason maturing genotype of southern Punjab (lat. $30^{\circ} 19^{\prime} 07.4^{\prime \prime} \mathrm{N}$, long. $\left.71^{\circ} 43^{\prime} 37.9^{\prime \prime} \mathrm{E}\right)$. The genotype has spreading tree growth habit with semicircular crown shape (Table 1). Young leaves are light green, mature leaves are green in color with ovate form and entire margins. The inflorescence is pyramidal having light green color (Fig. 1). The fruit is medium in size ( $362 \mathrm{~g}$ average weight) having $9.3 \mathrm{~cm}$ and $6.9 \mathrm{~cm}$ average length $\times$ breadth, respectively, with an attractive elliptic shape (Table 2). Pulp color is yellow orange having excellent eating quality with pleasant flavor. The stone is medium size (38.4 $\mathrm{g}$ average weight) covered with medium and soft fibers. The genotypespecific marker (MIAC4a) has been identified for KHW-251 (Table 3). Moreover, the DNA fingerprints of KHW-251 using 120 SSR primers are also available for its profiling.

MLT-239 is a midseason maturing chance seedling mango genotype of southern Punjab (lat. $30^{\circ} 14^{\prime} 55.5^{\prime \prime} \mathrm{N}$, long. $71^{\circ} 35^{\prime} 07.3^{\prime \prime} \mathrm{E}$ ) with a large fruit size. Tree has spreading growth habit having semicircular crown shape (Table 1). Young leaves are brick red, whereas, mature leaves green in color, lanceolate with acuminate tips and wavy margin. The inflorescence is pyramidal having light orange color. The fruit is large in size (450 g average weight) and having 13.9 and $7.4 \mathrm{~cm}$ average length $\times$ breadth, respectively, with attractive and narrowly elliptic shape. Pulp color is golden yellow, fibreless, good taste, pleasant flavor with high $2.1 \mathrm{~mm}$ Trolox/g FW average antioxidant contents (Table 2). The seed is medium (37.5 g average weight) with ellipsoid stone covered with a sparse, short and soft fibers. The DNA fingerprints of MLT-239 by using 120 SSR primers are now available for its profiling. The genotype-specific markers (mмiCIR010, mмiCIR018) have also been identified for MLT-239 (Table 3).

MLT-248 is a midseason maturing genotype grown in southern Punjab (lat. $30^{\circ} 14^{\prime} 51.6^{\prime \prime} \mathrm{N}$, long. $71^{\circ} 35^{\prime} 03.5^{\prime \prime} \mathrm{E}$ ). Tree has spreading growth habit with semicircular crown shape (Table 1). Young leaves are light green with brownish tinge, mature leaves are green ovate with wavy margin. The inflorescence is pyramidal having pink color (Fig. 1). The fruit is small in size (200 $\mathrm{g}$ average weight) and having 7.1 and $5.1 \mathrm{~cm}$ average length $\times$ breadth, respectively, with attractive oblong shape (Table 2). Pulp color is yellow orange, fibreless, excellent taste with pleasant flavor. Taste is similar to that of "Anwar Ratole' and would appeal to consumers as it matures later than 'Anwar Ratole'. The seed is small, fibreless, and oblong in shape with $23.3 \mathrm{~g}$ average weight. The genotype-specific markers (MilIHR04, mMiCIR005, mмiCIR036) have been identified for MLT-248 (Table 3). The DNA fingerprints of MLT-248 by using 120 SSR primers are also available for its profiling.

MLT-369 is a midseason genotype with a tremendous scope of adoption by the mango growers in southern Punjab (lat. $30^{\circ} 14^{\prime} 59.1$ "N, long. $\left.71^{\circ} 35^{\prime} 16.0^{\prime \prime} \mathrm{E}\right)$. Tree has erect growth with oblong crown shape. Young leaves are light brick red, whereas mature leaves are green in color having lanceolate form with wavy margin. The inflorescence is pyramidal having light orange color. The fruit is small in size ( $210 \mathrm{~g}$ average weight) having 9.4 and $5.0 \mathrm{~cm}$ average length $\times$ breadth, respectively, with narrowly elliptic shape 


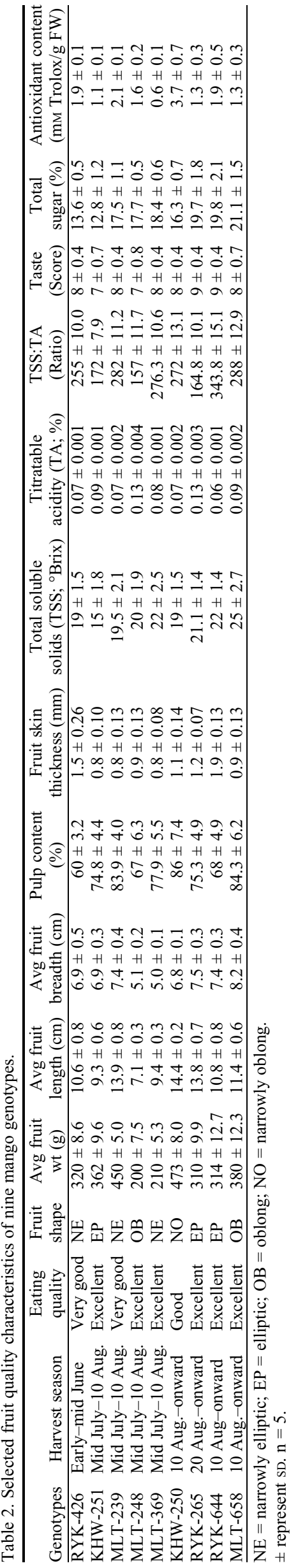

Table 3. Genotype specific marker for selected mango genotypes.

\begin{tabular}{|c|c|}
\hline Genotypes & Marker \\
\hline RYK-426 & MiIIHR15 \\
\hline KHW-251 & MIAC4a \\
\hline MLT-239 & mмiCIR010, mміCIR018 \\
\hline MLT-248 & MiIIHR04, mмiCIR005, mмiCIR036 \\
\hline MLT-369 & MiIIHR06a \\
\hline KHW-250 & mMiCIR006, LMMA-3 \\
\hline RYK-265* & - \\
\hline RYK-644 & mMiCIR009 \\
\hline MLT-658 & MiIIHR19 \\
\hline
\end{tabular}

*No genotype specific primer has been identified for this genotype.

(Table 2). Fruit exhibit excellent eating quality with high average 276 TSS:TA ratio (Table 2). The stone is small, fibreless, and ellipsoid in shape with $26.5 \mathrm{~g}$ average weight. The DNA fingerprinting of MLT-369 has been done by using 120 SSR primers for its profiling. The genotype-specific marker (MiIIHR06a) has also been identified for MLT-369 (Table 3).

KHW-250 is a stable late season maturing genotype developed as chance seedling, native to southern Punjab (lat. $30^{\circ} 19^{\prime} 09.7^{\prime \prime} \mathrm{N}$, long. $71^{\circ} 43^{\prime} 38.1^{\prime \prime} \mathrm{E}$ ) with large fruit size. Tree has spreading growth habit having semicircular crown shape (Table 1). Young leaves are light green, mature leaves green in color having lanceolate form. The Inflorescence is pyramidal with pink color. The fruit is large in size (473 $\mathrm{g}$ average weight) with 14.4 and $6.8 \mathrm{~cm}$ average length $\times$ breadth, respectively, and narrowly oblong shape with good eating quality and highest average antioxidant contents ( $3.7 \mathrm{~mm}$ Trolox/g FW), as compared with all other selected genotypes (Table 2). Stone is medium size ( $33.9 \mathrm{~g}$ ), ellipsoid with medium and soft fibers. The DNA fingerprints of KHW-250 by using 120 SSR primers are available for its profiling. The genotype-specific markers (mMiCIR006, LMMA-3) have also been identified for KHW-250 (Table 3).

RYK-265 is late season maturing genotype from southern Punjab (lat. $29^{\circ} 06^{\prime} 56.3^{\prime \prime} \mathrm{N}$, long. $\left.70^{\circ} 54^{\prime} 22.1^{\prime \prime} \mathrm{E}\right)$. Maturity time from 20 Aug. to onward makes it a good candidate for export oriented commercial plantation. It has erect growth habit with oblong crown shape (Table 1). Newly emerged young leaves of this genotype are light green in color; whereas, mature leaves are dark green with lanceolate leaf blade shape, semierect leaf attitude, and wavy margins. Inflorescence is broadly pyramidal having yellow color. Fruit is medium in size (310 g average weight), elliptic in shape with attractive and smooth yellow colored skin. Fruit is with acute apex having strong vertical stalk attachment with pointed beak and without neck prominence (Fig. 1). Pulp is juicy with mild aroma having short fibers of golden yellow color, excellent eating quality with fairly good average antioxidant contents (1.3 mm Trolox/g FW). TSS and TSS:TA ratio of the fruit are $21.1^{\circ}$ Brix and 164.8 , respectively (Table 2). The stone is medium (35.2 g), oblong covered with medium and soft fibers having veins level with the surface. The DNA fingerprints of RYK-265 by using 120 SSR primers are also available for its profiling.

RYK-644 is a late season maturing chance seedling genotype being identified from southern Punjab (lat. $29^{\circ} 07^{\prime} 04.01^{\prime \prime} \mathrm{N}$, long. $70^{\circ} 54^{\prime} 20.45^{\prime \prime} \mathrm{E}$ ). The original tree of this genotype has spreading growth habit with broadly pyramidal crown shape. Young leaves are light green with brownish tinge, whereas, mature leaves are green in color with obovate form and entire margin. Inflorescence is conical having light orange color (Fig. 1). Fruit is medium in size (314.0 g average weight) having 10.8 and $7.4 \mathrm{~cm}$ average length $\times$ breadth, respectively, with elliptic shape. The fruit pulp is yellow, fibreless with pleasant flavor, excellent eating quality, and very high average TSS:TA ratio (343) (Table 2). The stone is small, ellipsoid covered with short and soft fibers. The DNA fingerprints of RYK-644 by using $120 \mathrm{SSR}$ primers are available for its profiling. The genotype-specific marker (mмiCIR009) has been identified for RYK644 (Table 3).

MLT-658 is a late season maturing genotype of Punjab (lat. $30^{\circ} 00^{\prime} 49.66^{\prime \prime} \mathrm{N}$, long. $\left.71^{\circ} 20^{\prime} 31.44^{\prime \prime} \mathrm{E}\right)$. Tree has spreading growth habit with semicircular crown shape. Young leaves are light green, whereas, mature leaves are green in color with lanceolate form and wavy margin. The inflorescence is pyramidal with yellow color (Fig. 1). The fruit is medium in size (380 g average weight) having $11.4 \mathrm{~cm}$ and $8.2 \mathrm{~cm}$ average length $\times$ breadth, respectively, with oblong shape (Table 2). Pulp is juicy, creamy in color with short fiber, and pleasant flavor. It exhibits highest average TSS $\left(25^{\circ}\right.$ Brix) and total sugars $(21 \%)$ among all selected genotypes. The stone is medium in size (41.9 g) oblong covered with medium fibers. The genotype-specific marker (MiIIHR19) has been identified for MLT-658 (Table 3). The DNA fingerprints of MLT-658 by using 120 SSR primers are available for its profiling.

\section{Availability}

Plants of all the genotypes are currently commercially propagated and annually available through the Institute of Horticultural Sciences, University of Agriculture, Faisalabad, Pakistan. Plants of each genotype are readily available for distribution and commercialization. Individuals interested in obtaining budwood of indicated genotypes should contact the Institute of Horticultural Sciences, University of Agriculture, Faisalabad, 38040, Pakistan.

\section{Literature Cited}

Azmat, M.A., A.A. Khan, I.A. Khan, I.A. Rajwana, and A.S. Khan. 2016. Morphological characterization and SSR based DNA fingerprinting of elite commercial mango cultivars. Pak. J. Agr. Sci. 53:321-330.

Azmat, M.A., I.A. Khan, H.M.N. Cheema, I.A. Rajwana, A.S. Khan, and A.A. Khan. 2012. DNA extraction from mature leaves of Mangifera indica $\mathrm{L}$. suitable for PCR applications. J. Zhejiang Univ. Sci. B 13:239-243.

Chaikiattiytos, S., R. Kurubunjerdjit, P. Akkaravessapong, S. Rattananukul, P. Chueychum, 
and P. Anupunt. 2000. Improvement and evaluation of the selected 'KAEW SISAKET' mango in Thailand. Acta Hort. 509:185-192.

Horwitz, W. 1960. Official and tentative methods of analysis. Association of official agriculture chemists. 9th ed. Washington, DC.

Khan, A.S., S. Ali, and I.A. Khan. 2015. Morphological and molecular characterization and evaluation of mango germplasm: An overview. Sci. Hort. 194:1-14.

Khan, A.S. and Z. Singh. 2008. 1-Methylcyclopropene application and modified atmosphere packaging affect ethylene biosynthesis, fruit softening, and quality of 'Tegan Blue' plum during cold storage. J. Amer. Soc. Hort. Sci. 133:290-299.

Rajwana, I.A., I.A. Khan, A.U. Malik, B.A. Saleem, A.S. Khan, K. Ziaf, R. Anwar, and M. Amin. 2011. Morphological and bio-chemical markers for varietal characterization and quality assessment of potential indigenous mango (Mangifera indica L.) germplasm. Intl. J. Agr. Biol. 13:151158.

Rajwana, I.A., N. Tabbasam, A.U. Malik, S.A. Malik, M. Rahman, and Y. Zafar. 2008. Assesment of genetic diversity among mango (Mangifera indica L.) genotypes using RAPD markers. Sci. Hort. 117:297-301.
Peryam, D.R. and E.J. Pilgrim. 1957. Hedonic scale method for measuring food preferences. Food Technol. 11:9-15.

van Wyk, M., A.O. Al Adawi, I.A. Khan, M.L. Deadman, B.D. Wingfield, R. Ploetz, and M.J. Wingfield. 2007. Ceratocystis manginecans $s p$. nov., causal agent of a destructive mango wilt disease in Oman and Pakistan. Fungal Divers. 27:231-240.

Yamanaka, N., M. Hasran, D. H. Xu, H. Tsunematsu, S. Idris, and T. Ban. 2006. Genetic relationship and diversity of four Mangifera species revealed through AFLP analysis. Genet. Resources Crop Evol. 53:949-954. 